\title{
NILAI EKONOMI SUMBERDAYA PERIKANAN DI SULAWESI UTARA (Studi Kasus Ikan Cakalang, Katsuwonus pelamis) ${ }^{1}$
}

\author{
Economic Value of Fisheries Resources in North Sulawesi \\ (Case Study of Skipjack Tuna, Katsuwonus Pelamis)
}

\author{
Keren W Lumi ${ }^{2}$, Eddy Mantjoro ${ }^{3}$, Max Wagiu ${ }^{3}$
}

\begin{abstract}
Skipjack tuna or by local term called ikan Cakalang were recognized as a mayor fish resource landed in several producing area of North Sulawesi Province. This fish species have a great contributions to the local and regional economy as it were used as raw material for various fish processing industry such as frozen fish, simple smoked fish, katsuobushi, and skipjack canning plants. Skipjack fish has several trade name depend on the market area. In North Sulawesi market area is called cakalang while skipjack tuna known as the International trade name. Economic values of skipjack tuna can be trace back through micro and macro economics as well as from fisheries resources economics point of view. Based on this frame of mind than the present study is focus on the analysis of economic values of skipjack in term of its contribution on the local economy activities such as work absorbtion, fishing industry, fish processing industry, auxiliary industry and marketing institutions created to handle this fish resources. The research performed during the period of April up to September 2012. Bitung city was selected as the area of research based on the facts that this location have long been the mayor skipjack tuna fishing base as well as the center of fish processing industries which using skipjack tuna as their raw material. The result of study indicated that skipjack fish resources have a great economic value in term of creating investments in various aspects of economy in North Sulawesi province particularly its contribution in the economy of Bitung city administration area.
\end{abstract}

Keywords : Fisheries resources economics, skipjack tuna, economic value

\section{ABSTRAK}

Skipjack tuna atau yang disebut ikan cakalang dikenal sebagai sumberdaya ikan terbanyak didaratkan pada beberapa daerah produksi di Provinsi Sulawesi Utara. Spesies ikan ini memberikan kontribusi besar sekali baik bagi perekonomian skala lokal maupun karena berfungsi sebagai bahan baku bagi berbagai industri pengolahan seperti ikan cakalang asap, Ikan kayu (katsuobushi), dan pabrik pengolahan ikan kaleng. Spesies skipjack memiliki sejumlah nama dagang tergantung daerah pemasaran. Di pasaran wilayah Sulawesi Utara di kenal dengan nama dagang ikan Cakalang sedangkan istilah skipjack tuna di pakai sebagai nama dagang internasional. Nilai ekonomi Ikan Cakalang dapat ditelusuri melalui sudut pandang ekonomi mikro dan makro serta ilmu ekonomi sumberdaya perikanan. Bertolak dari kerangka berpikir tersebut maka penelitian

\footnotetext{
${ }^{1}$ Bagian dari skripsi

${ }^{2}$ Mahasiswa Program Studi Agrobisnis Perikanan FPIK-UNSRAT

${ }^{3}$ Staf pengajar Fakultas Perikanan dan IImu Kelautan Universitas Sam Ratulangi
} 
kali ini diarahkan pada upaya analisis nilai ekonomi sumberdaya ikan Cakalang dalam bentuk seberapa besar kontribusinya terhadap kegiatan perekonomian lokal seperti penyerapan tenaga kerja, dorongan investasi di sektor penangkapan, pengolahan, industri penunjang dan terbentuknya lembaga pemasaran yang menangani sumberdaya ikan ini. Penelitian telah dilaksanakan pada selang waktu antara bulan Mei hingga September 2012. Kota Bitung telah dipilih sebagai lokasi penelitian berdasarkan fakta bahwa daerah ini telah lama menjadi basis armada penangkapan ikan cakalang dan juga sebagai pusat industri pengolahan yang memanfaatkan ikan cakalang sebagai bahan baku utamanya. Hasil studi menunjukan bahwa sumberdaya ikan cakalang memang telah memberikan kontribusi ekonomi sangat besar dalam bentuk mendorong investasi pada berbagai aspek ekonomi di Sulawesi Utara terutama kontribusi terhadap perekonomian wilayah administrasi Kota Bitung

Kata kunci : ekonomi sumberdaya perikanan, ikan cakalang, nilai ekonomi

\section{PENDAHULUAN}

Ikan cakalang merupakan produk andalan Provinsi Sulawesi Utara yang bernilai ekonomis tinggi. Dikatakan demikian karena spesies ikan ini digunakan sebagai bahan baku oleh berbagai jenis industri pengolahan seperti cakalang fufu, ikan kayu, ikan kaleng, abon cakalang, dan masih banyak lagi produk olahan yang menggunakan ikan cakalang sebagai bahan baku. Untuk mengolah berbagai produk tersebut memerlukan pula investasi untuk membangun kapal, pabrik pengolahan, pabrik es, gudang beku dan lembaga pemasaran. Kegiatan investasi tersebut pada akhirnya menyerap banyak tenaga kerja sehingga banyak orang beroleh pendapatan yang pada gilirannya mendorong perekonomian makro regional bergerak maju dan berkembang pesat.

Ikan cakalang adalah nama dagang lokal Sulawesi Utara. Untuk wilayah pasar yang lebih luas dipakai skipjack tuna sebagai nama dagang internasional. Nama ini diambil dari bahasa Inggris, sedangkan nama ilmiah di sebut Katsuwonus pelamis di ambil dari bahasa Jepang yang artinya ikan keras. Secara biologis Ikan cakalang, suka hidup bergerombol (schooling fish), pemangsa yang rakus dan merupakan ikan perenang cepat lebih dari 10 mil per jam.
Secara ekonomis ikan cakalang memberikan kontribusi besar yang di tunjukan oleh sebagian besar masyarakat pesisir memiliki pekerjaan sebagai nelayan baik pada usaha penangkapan, pengolahan, perdagangan dan industri penunjang. Keadaan ini dapat dilihat jelas di Provinsi Sulawesi Utara khususnya di wilayah administrasi Kota Bitung,

Jenis alat tangkap yang digunakan untuk ialah huhate (pole and line) dan pukat cincin (purse seine). Selain menangkap ikan cakalang usaha perikanan tangkap di Kota Bitung juga memproduksi jenis ikan pelagis kecil, ikan pelagis besar, dan ikan karang. Semua ini berujung pada tumbuhnya investasi pada berbagai sektor usaha baik yang terkait langsung dengan industri perikanan maupun yang bersifat penunjang seperti pelabuhan komersial, transportasi, laboratorium, rumah sakit, bengkel bahkan restoran, hotel dan lain-lain.

Ikan cakalang juga tercatat sebagai komoditi ekspor baik dalam bentuk segar, beku maupun olahan. Dari kegiatan ekspor tersebut negara Indonesia khususnya Sulawesi Utara mendapat tambahan devisa yang penting bagi keseimbangan neraca perdagangan luar negeri. Devisa yang masuk ke Sulawesi Utara akan menyebabkan peningkatan kesejahteraan penduduk. 


\begin{abstract}
Daerah kota Bitung telah lama di kenal sebagai basis armada kapal penangkapan ikan cakalang sekaligus sebagai pusat industri pengolahan ikan. Atas dasar itu maka Kota Bitung diberi julukan kota perikanan, lebih khusus lagi kota cakalang. Bertolak dari berbagai realitas dan fakta yang telah di uraikan diatas maka timbul gagasan untuk melakukan penelitian di Kota Bitung yang terkait dengan sumberdaya ikan cakalang. Penelitian yang banyak dilakukan di Kota Bitung, masih sedikit yang memperhatikan dari sudut pandang ekonomi sumberdaya perikanan yaitu tentang nilai ekonomi sumberdaya ikan cakalang. Oleh sebab itu perlu untuk melakukan suatu studi yang fokus pada ekonomi sumberdaya ikan cakalang dengan penekanan perhatian pada aspek kontribusinya pada perekonomian Kota Bitung maupun Sulawesi Utara.
\end{abstract}

\section{METODE}

\section{Waktu dan Lokasi Penelitian}

Penelitian dilaksanakan pada tanggal 1 Mei sampai dengan 30 September 2012. Lokasi pelaksanaan studi adalah Kota Bitung, Provinsi Sulawesi Utara. Penetapan ini didasarkan pada hasil survei awal yang menemukan bahwa Kota Bitung merupakan basis utama armada penangkapan ikan Cakalang dan pusat industri pengolahan hasil perikanan.

\section{Dasar Penelitian}

Penelitian ini berdasar pada studi kasus karena wilayah penelitian yang terbatas hanya pada wilayah administrasi Kota Bitung. Studi yang dilakukan dengan cara mempelajari satu kasus tertentu dan pada obyek atau wilayah yang terbatas pula disebut studi kasus yaitu dengan cara mengambil satu bagian dari populasi dan meneliti secara mendalam sifat-sifat yang terdapat pada satu bagian populasi itu. Sebagai konsekwensinya hasil studi tidak dapat digeneralisasi untuk keseluruhan populasi (Mantjoro, 1980).

\section{Pengumpulan Data}

Data yang dikumpulkan selama penelitian dilakukan dengan cara atau metode observasi langsung, terdiri dari data primer dan sekunder. Data primer di kumpulkan dari responden yang terlibat langsung adalah data yang diperoleh dari pengamatan langsung dilapangan langsung dengan data suberdaya ikan cakalang, seperti nelayan, pengusaha, dan pegawai dari instansi terkait. Data sekunder dikumpulkan dengan cara meminta fotokopi atau salinan dokumen, catatan, risalah yang di simpan oleh dinas dan instansi terkait.

\section{Analisa Data}

Data yang ada dianalisis dengan bantuan metode penguraian untuk data kualitatif atau (Qualitative descriptive method). Sedangkan untuk data kuantitatif digunakan metode statistika sebagai alat analisis (Statistical analysis method). Analisis uraian kualitatif yaitu upaya memberikan keterangan dan gambaran melalui uraian sesuai dengan data dan informasi yang terkumpul. Sedangkan analisis kuantitatif ialah dengan menggunakan dan melakukan sejumlah perhitungan matematika sederhana untuk membuat intisari dalam bentuk grafik..

\section{HASIL DAN PEMBAHASAN}

Catatan statistik hasil penelitian memberi petunjuk bahwa penduduk Kota Bitung menekuni banyak ragam mata pencaharian sesuai dengan keahlian dan ketrampilan masing-masing, seperti tertera pada Tabel 1.

Sebetulnya lebih dari 30 persen penduduk bekerja di sektor perikanan karena lapangan kerja lainnya yang tertera pada Tabel 1 terkait dengan perikanan, misalnya perdagangan, dimana sebagian besar adalah dagang ikan, demikian juga transportasi menekuni angkutan ikan, sehingga mereka yang bekerja di lapangan industri tidak lain adalah industri pengolahan ikan. Jika 
ditotalkan ada sekitar $80 \%$ bekerja di sektor perikanan.

\section{Serapan Tenaga Kerja}

Tenaga kerja adalah orang yang siap masuk dalam pasar kerja sesuai dengan upah yang ditawarkan oleh penyedia pekerjaan. Jumlah tenaga kerja dihitung dari penduduk usia produktif (umur 15-65 thn) yang masuk kategori angkatan kerja (Suharto, 2009).

Tersedianya lapangan kerja baru untuk mengatasi peningkatan penawaran tenaga kerja merupakan salah satu target yang harus dicapai dalam pembangunan ekonomi daerah. Upaya tersebut dapat diwujudkan melalui peningkatan pertumbuhan ekonomi khususnya investasi langsung (direct investment) pada sektor-sektor yang bersifat padat karya, seperti konstruksi, infrastruktur maupun industri pengolahan. Sementara pada sektor jasa, misalnya melalui perdagangan maupun pariwisata. Hasil studi terhadap daya serap tenaga kerja di kota Bitung seperti terlihat pada Tabel 2 .

\section{Industri Penangkapan}

Hanneson (1988), menyatakan bahwa usaha perikanan adalah suatu perpaduan produksi atau sebagai suatu barang yang dihasilkan faktor produksi klasik tenaga kerja dan barang modal atau apapun yang dianggap jenis ini.

Pemanfaatan teknologi penangkapan sangat tergantung pada kemampuan modal dan ketrampilan nelayan dalam menggunakannya. Tidak semua lapisan masyarakat dapat memanfaatkan teknologi penangkapan modern. Sementara laut sebagai sumber daya milik bersama (common property resources) tidak memiliki batasan wilayah yang jelas. Dalam kondisi demikian, sering terjadi benturan atau konflik diantara para nelayan yang sangat tergantung secara ekonomis terhadap laut (Agusta, 2009).

Sebagian warga wilayah pesisir Kota Bitung memiliki pekerjaan sebagai nelayan. Industri penangkapan sangat berperan penting dalam menghasilkan suatu barang dan jasa. Sehingga tenaga kerja yang diserap pada industri penangkapan sangat banyak, khususnya kapal penangkap ikan yaitu huhate (pole and line) dan pukat cincin (purse seine).

Pada tahun 2011 jumlah kapal huhate (pole and line) sebanyak 40 unit jumlah tenaga kerja 625 jiwa, dan kapal penangkap pukat cincin (purse seine) berjumlah 152 unit dengan jumlah tenaga kerja 1.300 jiwa yang tersebar di seluruh Kota Bitung.

\section{Industri Pengolahan}

Industri pengolahan ikan cakalang sangat berperan dalam pembangunan perekonomian Kota Bitung. Untuk Ikan cakalang diolah oleh beberapa pengolahan modern dan pengolahan tradisional. Pengolahan modern sampai saat ini berjumlah 17 unit yang terdiri dari pengolahan ikan kayu, ikan beku, dan ikan kaleng yang tersebar di seluruh Kota Bitung. Sedangkan pengolahan industri kecil yaitu usaha cakalang fufu yang sampai saat ini berjumlah 7 unit usaha.

Sebuah pabrik pengolahan ikan biasanya mengolah beberapa jenis olahan seperti pabrik milik PT. Perikanan Nusantara dan PT. Deho Canning Co., yang mengolah tiga jenis pengolahan ikan. Perusahaan perikanan yang banyak menyuplai bahan baku ikan cakalang yaitu PT. Bintang Mandiri Bersaudara. Perusahaan ini banyak mendistribusi ke perusahaan-perusahaan besar di Kota Bitung maupun luar kota seperti PT. Nichindo Suisan yang berada di Amurang, Minahasa Selatan.

\section{Volume Produksi Ikan Cakalang}

Volume produksi perikanan tangkap adalah jumlah ikan yang telah ditangkap dari sumberdaya perikanan alami oleh perusahaan atau rumah tangga perikanan tangkap (Anonim, 2011) Ikan cakalang merupakan komoditas andalan yang dijadikan sebagai umpan. Produksi ikan cakalang dalam lima tahun terakhir dapat dilihat pada Tabel 3. 
Dari Tabel 3 dapat disimpulkan bahwa jumlah perikanan tangkap ikan cakalang mengalami penurunan pada tahun 2009 sampai 2011. Ini sebabkan adanya perubahan cuaca dan ruaya ikan yang berubah-ubah sehingga produksi ikan cakalang tidak stabil.

\section{Fasilitas Penunjang}

Fasilitas yang dibangun untuk industri penangkapan di Kota Bitung berupa galangan kapal, bengkel kapal, TPI, pelabuhan perikanan, pabrik es, balai pengujian hasil perikanan dan stasiun karantina ikan.

Sarana penunjang sangat penting untuk perkembangan perekonomian khususnya bidang perikanan. Sehingga perlu dibangun sarana-sarana penunjang seperti di atas. Terbentuknya sarana penunjang seperti galangan kapal, pabrik es, dermaga dan TPI di dekat pelabuhan dapat memberikan manfaat bagi nelayan, karena nelayan tidak perlu ke pusat kota untuk mendapatkan bahan yang dibutuhkan saat melaut (Anonim, 2009).

\section{Lembaga Pemasaran}

Lembaga pemasaran merupakan badan yang menyelenggarakan kegiatan atau fungsi tataniaga yaitu barangbarang bergerak dari pihak produsen sampai pihak konsumen. Pedagang perantara dan lembaga pemberi jasa termasuk dalam lembaga pemasaran.

Hasil tangkapan nelayan khususnya ikan cakalang didaratkan ke TPI. Semua ikan yang terkumpul dilelang kemudian pedagang besar membeli ikan dan disalurkan ke pedagang pengecer, kemudian diteruskan ke konsumen. Adapun sebagian hasil tangkapan ikan langsung dijual ke perusahaan perikanan, diolah menjadi ikan olahan seperti ikan kaleng, ikan beku, ikan kayu dan ikan asap. Umumnya ikan olahan akan diekspor.

Pemasaran hasil perikanan di Kota Bitung berupa produk ikan segar dan produk beku. Daerah tujuan pemasaran meliputi wilayah sekitar Kota Bitung (pasar tradisional/modern), maupun luar pulau dan eksport. Pema- saran hasil perikanan ke luar negeri dilakukan oleh pengusaha perikanan yang ada di Kota Bitung, dengan tujuan ekspor yaitu Jepang, Jerman, Inggris, Belanda, Amerika, Eropa, Korea, Cina, Taiwan, Slovenia, Filipina, Kuwait, Afrika dan Denmark

\section{KESIMPULAN}

Sumberdaya ikan cakalang mempunyai nilai ekonomis tinggi yang ditunjukan oleh sekitar $30 \%$ penduduk memilih mata pencaharian sector perikanan, 7.335 jiwa, bekerja pada perusahan penangkapan, pengolahan, perdagangan dan lembaga pemasaran, serta besarnya Investasi yang ditanamkan untuk membuat kapal penangkap ikan sebanyak 192 unit, baik dari kapal Huhate maupun Pukat cincin.

Nilai ekonomis ikan cakalang juga dapat terbaca dari nilai produksi sekitar 2.9 trilyun rupiah pada tahun 2011 yaitu nilai dari $47.288,9$ ton ikan cakalang.

Pemasaran ikan cakalang mendominasi kegiatan perdagangan di kota Bitung dimana 15,647 jiwa atau 20\% dari jumlah penduduk bekerja di sektor ini. Hasil perikanan khususnya ikan cakalang memiliki nilai eksport yang tinggi.

\section{DAFTAR PUSTAKA}

Agusta, F. 2009. Konflik pemanfaatan Sumberdaya Perikanan Laut. http://ferragusta.wordpress.com/20 09/12/04/konflik-pemanfaatansumber-daya-perikanan-lautkasus-nelayan-diperairan-utarajawa-timur.html

Anonim, 2009. Laporan Tahunan 2009. Dinas Kelautan dan Perikanan Kota Bitung. $42 \mathrm{Hal}$

Anonim, 2011. Laporan Statistik Pelabuhan Perikanan Samudra. DitJen Perikanan tangkap. $55 \mathrm{Hal}$ 
Hanneson, R. 1988. Ekonomi Perikanan. Universitas Forlaget/UI. Jakarta $121 \mathrm{Hal}$

Mantjoro, E. 1980. Metodologi Penelitian. Pengantar Kuliah Metodologi
Penelitian. FPIK Unsrat. Manado. $65 \mathrm{Hal}$

Suharto. 2009. Pekerja Sosial di Dunia Industri. Bandung : PT Refika Aditama

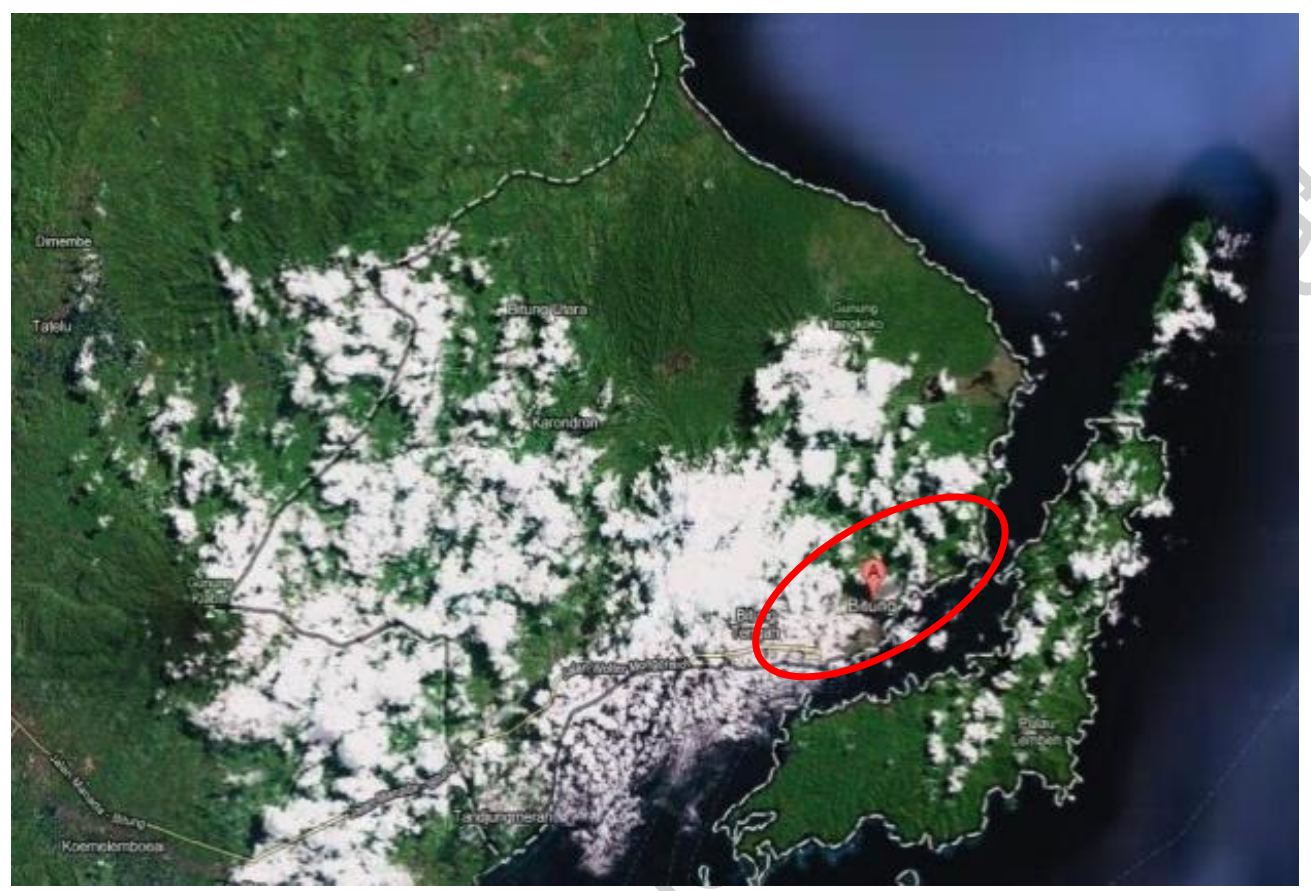

Gambar 1. Lokasi penelitian Kota Bitung.

Tabel 1. Jumlah penduduk menurut lapangan pekerjaan

\begin{tabular}{|c|l|c|c|}
\hline No & Lapangan kerja & jumlah & Persen (\%) \\
\hline 1 & Perikanan & 22,771 & 30 \\
\hline 2 & Perdagangan & 15,467 & 20 \\
\hline 3 & Transportasi & 11,914 & 16 \\
\hline 4 & Jasa & 10,084 & 13 \\
\hline 5 & Industri & 6,650 & 8 \\
\hline 6 & Konstruksi & 5,076 & 7 \\
\hline 7 & Pertanian & 1,256 & 2 \\
\hline 8 & Keuangan & 1,224 & 2 \\
\hline 9 & Pertambangan & 488 & 1 \\
\hline 10 & Listrik & 476 & 1 \\
\hline \multicolumn{2}{|c|}{ Jumlah } & 75,406 & 100 \\
\hline
\end{tabular}


Tabel 2. Serapan Tenaga Kerja

\begin{tabular}{|c|l|c|cr|}
\hline \multirow{2}{*}{ No } & \multicolumn{2}{|c|}{ Jenis Usaha } & \multirow{2}{*}{ Tenaga Kerja } & \multicolumn{2}{|c|}{ Nilai Ekonomi (Rp) } \\
& & & \multicolumn{2}{|c|}{} \\
\hline 1 & Huhate (pole and line) & 625 & $\mathrm{Rp}$ & 937.500 .000 \\
\hline 2 & Pukat cincin (purse seine) & 1.300 & $\mathrm{Rp}$ & 1.950 .000 .000 \\
\hline 3 & Cakalang Fufu & 135 & $\mathrm{Rp}$. & 202.500 .000 \\
\hline 4 & lkan Kaleng & 1.150 & $\mathrm{Rp}$. & 1.725 .000 .000 \\
\hline 5 & ikan Kayu & 1.230 & $\mathrm{Rp}$. & 1.845 .000 .000 \\
\hline 6 & lkan Beku & 2.250 & $\mathrm{Rp}$. & 3.375 .000 .000 \\
\hline 7 & Pedagang besar & 122 & $\mathrm{Rp}$ & 18.300 .000 .000 \\
\hline 8 & Pengumpul & 120 & $\mathrm{Rp}$. & 18.000 .000 .000 \\
\hline 9 & Pengecer & 403 & $\mathrm{Rp}$. & 60.450 .000 .000 \\
\hline \multicolumn{2}{|c|}{ Jumlah } & 7.335 & Rp. 105.941 .4250 .000 \\
\hline
\end{tabular}

Tabel 3. Produksi Ikan Cakalang

\begin{tabular}{|c|r|r|}
\hline Tahun & Produksi (Ton) & Nilai Ekonomi (Rp) \\
\hline 2007 & 57.360 .1 & 458.880 .800 .000 \\
\hline 2008 & $57.820,6$ & 520.385 .400 .000 \\
\hline 2009 & $47.876,0$ & 430.884 .000 .000 \\
\hline 2010 & $47.382,1$ & 450.129 .950 .000 \\
\hline 2011 & $47.288,9$ & 496.533 .450 .000 \\
\hline Jumlah & 257.727 .7 & 2.356 .813 .600 .000 \\
\hline
\end{tabular}

